\title{
An investigation on social accountability of general medicine curriculum
}

\author{
Ali Emadzadeh ${ }^{1}$, Hossein Karimi Moonaghi ${ }^{2}$, Mojtaba Mousavi Bazzaz ${ }^{3}$, Sharareh Karimi ${ }^{4}$
}

${ }^{1}$ Ph.D. of Health Education, Assistant Professor, Department of Medical Education, Faculty of Medicine, Mashhad University of Medical Sciences, Mashhad, Iran

${ }^{2}$ Ph.D. of Nursing Education, Associate Professor, Evidence-Based Caring Research Center, Department of Medical-Surgical Nursing, School of Nursing and Midwifery, Department of Medical Education, School of Medicine, Mashhad University of Medical Sciences, Mashhad, Iran

${ }^{3}$ M.D., Associate Professor, Department of Community Medicine, Faculty of Medicine, Mashhad University of Medical Sciences, Mashhad, Iran

${ }^{4}$ M.Sc. of Medical Education, Department of Medical Education, Mashhad University of Medical Sciences, Mashhad, Iran

\section{Type of article: Original}

\begin{abstract}
Introduction: Experts consider social accountability as a new paradigm in medical education and a cultural change that is necessary to be studied and understood more deeply. One of the problems of medical education is the inadequacy of medicine graduates to meet the social accountability. Therefore, the aim of this study was to examine the general medicine curriculum for social accountability.

Methods: This cross-sectional study was conducted on three groups of experts, faculty members, and general physicians working in health centers in Mashhad in 2014. According to the needs assessment and definition of need as a requirement or preference, the research was conducted in three stages using the Delphi method, in which the opinions of experts, lecturers, and practitioners were collected and classified based on the CARE model in four areas, i.e., clinical activities, advocacy, research, and educational categories, and, ultimately, the percentage of agreement was determined.

Results: As indicated by the results of the need analysis, in order to reach social accountability of medical students of Mashhad University of Medical Sciences, the curriculum should cover four major areas, i.e., clinical activities, advocacy, research, and training. We found 38 items for social accountability that are required in the general medical curriculum, including clinical activities (12 items), advocacy (10 items), and scope of research ( 8 items). The educational area was comprised of 8 items. In this study, from 30 participants, only 19 people participated in the three-step Delphi, and there was a $70 \%$ response rate in the first stage and second stage, but $90.47 \%$ in the third stage.

Conclusion: There is a growing interest around the world for social accountability in medical schools and other health-related schools. It is expected that the results will be of interest to planners and policy-makers in this field so that we will observe a promotion in the culture of social accountability in Mashhad University of Medical Sciences.
\end{abstract}

Keywords: Educational needs, General medicine curriculum, Social accountability, CARE model

\section{Introduction}

With the advent of a new concept for health and hygiene along with global developments in medical education that were initiated in a global meeting in Almaty (Kazakhstan) in 1978, the Primary Health Care (PHC) strategy as the first step in achieving the health for all aim up to the year 2000 was suggested (1). Then, the resolutions of the world gathering in Edinburgh, Scotland, in 1988 showed the necessity of a change in the medical education programs based on the needs of society, and the modern role of the physician caused changes in medical educational

\section{Corresponding author:}

Sharareh Karimi, Department of Medical Education, Mashhad University of Medical Sciences, Mashhad, Iran. Tel: +98.9153721875, Fax: +98.5138415222, Email: karimish1@mums.ac.ir and karimisharareh537@yahoo.com Received: September 30, 2015, Accepted: December 05, 2015, Published: July 2016 iThenticate screening: December 21, 2016, English editing: April 16, 2016, Quality control: June 05, 2016 (C) 2016 The Authors. This is an open access article under the terms of the Creative Commons Attribution-NonCommercialNoDerivs License, which permits use and distribution in any medium, provided the original work is properly cited, the use is non-commercial and no modifications or adaptations are made. 
programs. This should be in a way that graduates' abilities are enhanced in terms of identifying society's health problems and to maintain and increase people's health care, thereby leading to changes in the general medical training programs (1). The social accountability strategy tries to improve organizational performance by supporting the participation of citizens and accountability for policymakers in the public and private sectors. In practice, the concept of social accountability includes a wide range of innovation and creativity (2). The concept of social accountability in response to a great wish for social justice in health care has many proponents in medical schools (3). Paying even more attention to the role of social factors in society's health has resulted in the fact that the role of physicians, in addition to providing diagnostic and therapeutic services, has increased relative to leadership of the community in terms of health and health-related issues. Currently, the growth and rapid changes in medical knowledge are occurring so rapidly that the knowledge of a medical student is only sufficient for a brief time after graduation considering quality and up-to-date practices. Thus, another role is defined for practitioners, which is the management of medical knowledge. Physicians of the third millennium should be able to obtain their patients' information in a short time and investigate its validity and reliability in taking care of the patients. The explosion of information in the health sector, the increasing complexity of the health system, the change in disease patterns, and the population that is becoming older, globalization, the advent of new technology, and the increase of costs in health care have caused medical educators to implement certain changes to adapt to the changing situation $(4,5)$. Therefore, the biggest challenge of medical colleges in the future is their need to attempt to show more effects on health through a linked relationship with the community, which is the social accountability objective (6). The World Health Organization in 1995 established new tasks for students, teachers, and educational planners by entering the society as a main factor in medical education and defined social accountability, i.e., 'guided training, research and services in order to satisfy the health needs and priorities of the community, region or nation that have the service commitment' (7). Today, the accreditation institutes, by developing evaluation indicators and performing foreign evaluations, have provided great help for the educational institutions. These institutes could be good motivators for educational institutions to pay attention to these issues by setting up appropriate indicators regarding the social response. The Global Consensus for Social Accountability of Medical Schools (GCSA) program has clearly considered the accountability of educational institutions for social response of the curriculum. In Iran, in the ninth accountability standard of medical education centers for research and development programs, there has been an emphasis on providing organized programs for developing an accountable education in medical universities (8). Although the general principles of social accountability were provided over a decade ago, they rarely have been applied in medical schools (6). The results of research conducted at a medical school in Iran regarding the social accountability in education section showed that social accountability is at a relatively favorable level. This situation was undesirable in the design phase, relatively favorable while being conducted, and was desirable in the consequence stage (9), and, since one of the initial stages of proper designing is proper investigation of the needs, in this research, we investigated the educational program needs of a general medical training course for social accountability in Mashhad Medical School in 2015.

\section{Material and Methods}

\subsection{Research design and setting}

This was a cross-sectional study performed on three groups, i.e., experts, faculty members, and general physicians, working in the health centers of Mashhad in 2014. The study was conducted with regard to needs assessment with consensus method in three stages. The Delphi method is a useful approach for developing consensus among a relatively large group of participants (10). Moreover, this method has been used extensively in the development of educational programs $(11,12)$.

\subsection{Instrument}

The research instrument was a questionnaire that was prepared using valid texts and resources. For content and face validity of the questions in the first stage, five experts and scholars in medical education and social accountability were identified, and, then, the necessary modifications of the tools were conducted. The reliability coefficient for the questionnaire's items based on Cronbach's alpha coefficient was 95\%. The questionnaire consisted of demographic information (age, gender) and the above-mentioned four areas designed based on the CARE model. Clinical activities, advocacy, research, and training areas consisted of open-ended questions. In fact we asked broad questions. We asked questions such as, "What clinical work do you do that you consider socially accountable? What advocacy work do you do for social accountability? What aspects of your research agenda are socially accountable? How do you integrate social accountability into your education and training programs?" e.g., community servicelearning, dedicated lectures. We looked more at the medical school as a whole and asked what elements apply to these issues and where there are gaps that should be addressed. 


\subsection{Data collection}

In the first stage, basic questions were sent (via email or fax) in an unstructured or open-ended format for the sample population, and they were asked to brain storm and express their ideas freely and then return their responses. Moreover, if necessary, we asked the questions face to face. When the responses were collected, they were organized by combining similar views, eliminating repeated issues, and making the responses as short as possible. If necessary, reminder emails were sent to individuals or phone calls were made as reminders. Moreover, the CARE model was used to classify content. The CARE model is for identifying the social accountability, which identifies four important areas for social accountability measures, including clinical activities, advocacy, research and education, and training. Therefore, the responses were classified into four groups based on these areas. In the second stage, we used a structured questionnaire, and the responses that were received were sent to people who were asked to rate the responses using a Likert scale. At this point, the agreement and disagreement areas were identified. After collecting the questionnaires, the summary of statistics and rankings was provided. In the third stage, the results of the second phase were sent to the participants, and they were asked to review the responses again and to revise their comments and judgments, if necessary, and to mention their reasons for the lack of consensus and grade their importance considering the mean and median scores. Finally, the comments were finalized, and the items listed for each area for social accountability were identified based on the ideas of the target group. At this stage, the final results were prepared and published.

\section{Results}

After collecting the data in three stages using the Delphi method, the final results were determined as follows: In this study, only 19 people out of 30 selected people were involved in all three phases. Different participants' ages were $50.5 \pm 6.92$ for experts, $44.4 \pm 6.67$ for faculty members, and $37.6 \pm 3.97$ for general physicians. The average age was $44.1 \pm 6.45$. The participants were $73.69 \%$ males and $26.31 \%$ females. In total, according to the results, 12 items in the scope of clinical activities, 10 items in advocacy activities, 8 items in research activities, and 8 items were identified in the educational activities. As indicated by the results of the needs analysis conducted in the present study, in order to reach social accountability of medical students of Mashhad University of Medical Sciences, the curriculum must cover four major areas, including clinical activities, advocacy, research, and training. Among others, clinical activities comprised of 12 items among which "familiarizing students with common diseases, epidemiologic transition of disease, and change of the disease burden in society" and "Early exposure of students to health problems (e.g., due to working in Drop In Centers (DIC), high-risk behavior counseling centers, community oriented health centers, and shelter mayoralty) showed the highest (84.3\%) and the lowest $(15.79 \%)$ percentage of agreement, respectively (Table 1).

Table 1. Percentage of comments regarding the general medicine curriculum requirements for social accountability based on Clinical Activity Area

\begin{tabular}{|l|l|}
\hline Clinical Activity Area & $\begin{array}{l}\text { Agreement } \\
\text { percentage }\end{array}$ \\
\hline $\begin{array}{l}\text { To familiarize students with common diseases, epidemiological transition of disease, changes in } \\
\text { disease burden in the community }\end{array}$ & 84.3 \\
\hline $\begin{array}{l}\text { Clinical skills including checking the history, physical examination, actions and investigations, } \\
\text { emergency practices and communication and leadership skills }\end{array}$ & 78.95 \\
\hline Good communication skills with patients & 73.69 \\
\hline Dealing with outpatients besides the clinical patients & 73.69 \\
\hline $\begin{array}{l}\text { To apply the principles of prevention, screening, diagnosis, treatment and rehabilitation of patients } \\
\text { in the community }\end{array}$ & 63.15 \\
\hline Conducting internship or training in rural health centers, clinics and emergency 115 & 52.63 \\
\hline Clinical responsibilities including health promotion, prevention and patient care & 47.37 \\
\hline Appropriate system for referral & 47.37 \\
\hline $\begin{array}{l}\text { Patient management (considering the patient and Individuals as well as families social problems } \\
\text { and damages) }\end{array}$ & 36.85 \\
\hline Writing prescriptions and other medications & 36.84 \\
\hline $\begin{array}{l}\text { Understanding the behavioral ,social and medical ethics sciences depending on local needs and } \\
\text { traditions }\end{array}$ & 15.79 \\
\hline $\begin{array}{l}\text { Early exposure of students with health problems DIC center for health, (activity in high-risk } \\
\text { behavior counseling centers, and community based health centers, green houses, etc.) }\end{array}$ & 15.79 \\
\hline
\end{tabular}


Advocacy area included 10 items among which "Community-oriented medical education" and "Familiarizing students with insurance systems and people working in charities," respectively, demonstrated the highest (42.11\%) and the lowest $(0 \%)$ percentage of agreement. Within the scope of the research, there were 8 items, including "Conducting key research regarding social health-related issues" with the highest percentage of agreement (47.37\%) and "The importance of community-based studies" with the lowest (15.79\%) percentage of agreement. Finally, educational area comprises of 8 items, including "Using community-based, outpatient medical education, problemoriented and holistic models" with the highest (52.63\%) and "Continuing education through continuous education programs, continuous study, etc." with the lowest (5.26\%) percentage of agreement (Tables 1-4).

Table 2. Percentage of comments regarding the general medicine curriculum requirements for social accountability based on Advocacy Area

\begin{tabular}{|l|l|}
\hline Advocacy area & $\begin{array}{l}\text { Agreement } \\
\text { percentage }\end{array}$ \\
\hline Community oriented medical education & 42.11 \\
\hline Strengthening the holistic rather than patient oriented medicine & 36.85 \\
\hline $\begin{array}{l}\text { Participation in patient care including appropriate social experience and team work with other } \\
\text { health professions }\end{array}$ & 21.05 \\
\hline The skills of attracting others for participation & 10.53 \\
\hline $\begin{array}{l}\text { Non-curriculum activities (sport groups, membership in NGOs and school administrative tasks, } \\
\text { etc.). }\end{array}$ & 10.52 \\
\hline $\begin{array}{l}\text { The inclusion of topics such as social determinant of health and the relationship between health } \\
\text { and social equalities }\end{array}$ & 5.26 \\
\hline Conducting practical courses such as summer camps in rural areas and suburbs & 5.26 \\
\hline Including a variety of instructors from health and social sciences discipline & 0 \\
\hline familiarizing students with health partners & 0 \\
\hline Familiarizing students with insurance systems and people working in charities & 0 \\
\hline
\end{tabular}

Table 3. Percentage of comments regarding the general medicine curriculum requirements for social accountability based on Research Area

\begin{tabular}{|l|l|}
\hline Research area & $\begin{array}{l}\text { Agreement } \\
\text { percentage }\end{array}$ \\
\hline Conducting key research regarding societies health-related issues & 47.37 \\
\hline Conducting researches studies at the hospital with clinical priority cases & 36.85 \\
\hline Emphasis on the investigation and study on the needs and priorities of the society & 31.58 \\
\hline Research focus on the optimization of the principles of care required for peoples health & 31.58 \\
\hline The principles of the need assessment and how to apply them & 26.32 \\
\hline Providing a base to record students research ideas & 26.32 \\
\hline $\begin{array}{l}\text { Creating the ability for students to design and express scientific questions in any clinical area and } \\
\text { then collect scientific evidence }\end{array}$ & 26.31 \\
\hline The importance of community-based studies & 15.79 \\
\hline
\end{tabular}

Table 4. Percentage of comments regarding the general medicine curriculum requirements for social accountability based on Education Area

\begin{tabular}{|l|l|}
\hline Education area & $\begin{array}{l}\text { Agreement } \\
\text { percentage }\end{array}$ \\
\hline Using community-based, outpatient medical education, problem-oriented and holistic models & 52.63 \\
\hline Conversion of general medicine from GP to MD & 42.10 \\
\hline $\begin{array}{l}\text { Using training programs for emphasis and representing professionalism and ethics issues in } \\
\text { medicine }\end{array}$ & 36.84 \\
\hline Field work and familiarity with basic health problems and determined priorities of the region & 36.84 \\
\hline Using a combination of teacher-student based strategies, society based strategies & 26.31 \\
\hline Primary health care (PHC) & 26.31 \\
\hline Submitting at least 50 family files to each student as training for health care & 21.05 \\
\hline Continuing education through continuing education programs and continuous study & 5.26 \\
\hline
\end{tabular}




\section{Discussion}

There is a growing interest around the world in social accountability in medical schools and other health-related colleges (4). According to the results, 12 items were identified as the training needs in the clinical activities areas. The first item in clinical activities area was to familiarize students with common diseases, epidemiological transition of diseases, and changes in the burden of diseases in the community. In Iran, general practitioners should manage the provision of medical services to individuals. Additionally, as the next priorities, the second up to the twelfth row emphasize on some important points including students clinical activities in terms of social accountability, the formation of medical schools' contents based on societies' priorities, and medical courses as being integrated (horizontal, vertical) and taught in health centers, clinics, hospitals and classrooms. In this, we can ensure that students become familiar with the communities in which they work, and they notice their health needs and how to react or dissolve their issues $(13,14)$. However, some amendments in Mashhad Medical School are recommended based on our investigation of the educational curriculum for medical education, such as the horizontal integration of some courses in the basic sciences and pathogenesis, as well as clinical teaching of hospitals and toward teaching to clinics. This is a very encouraging issue that the authorities in universities have felt the need for changes of the curriculum of medical students in line with the changes in recent years around the world, including changes in the growing population, the face of the population, and thus changing the face of diseases and injuries and health needs of community. Therefore, the need for close scrutiny was considered in the medical education programs of Mashhad University of Medical Sciences. Holmqvist et al. noted in their article that one of the ways to increase the social accountability of medical education is a comprehensive direct confrontation with the problems of society. Since the decade of the 1960s, medical schools have established clinics in society in which physicians are trained with other professionals and serve society at the same time (15). Moreover, in the advocacy area, 10 items were identified as priorities, and the first priority emphasizes community-based medical education. Yamani et al. concluded in their paper that social accountability must be seen as medical universities' main missions, and the first step in the development of accountability is to identify the needs of society (8). Emadzadeh et al. noted that communityoriented issues in medical education meeting the actual needs of the community has confronted a chaotic way. Therefore, medical education in this regard should be concerned extensively and deeply. Community orientation is a concept that is more than ever required to provide services in the field of medical science (9). In medical sciences fields, there is more quantitative paradigm in which its importance is more in the empirical sciences compared to humanities. Professionalism, accountability, altruism, and empathy that are important indicators of the accountability of doctors are not considered much in quantitative paradigms. Therefore, the medical education curriculum is poor in terms of humanistic insights. Medical schools expect that doctors and students appreciate professional values both in clinics and in society. This is while the students have not learned these things even superficially. In addition, little attention has been paid to the concept of community's medical support (advocacy) in the medical curriculum or in social science education, which is closely related to accountability (16-18). Based on the results, 8 items were identified in the research area, and the first one emphasizes the investigation and study of needs and society's priorities. Rezaeian stated in his article that research is one of the activities of medical schools that usually is conducted in the areas of clinical and basic sciences. According to the research conducted in medical schools and despite paying attention to social problems covered by them, this kind of research does not have the necessary focus in medical schools (19). Collier, Boelen, and Woollard also emphasized the responsibility of medical schools toward society and expressed that, in addition to conducting research in the basic and clinical sciences, there should be an endeavor toward the priorities regarding the society's health (20, 21). Moreover, eight items are identified regarding the results of educational activities area. The first priority is regarding the use of the community-based models, outpatient medical education, and problem-based, holistic education. Ghaffari et al. concluded in their research that the use of new and effective educational practices, such as the use of problem solving-based learning (PBL) or small group discussions are the most prevailing educational practice in our country in the big groups that is most observed in basic science. This is while most of the medical schools that are prominent in the world have tried to transform teaching practices from lecture-based teaching to problem solving-based teaching and discussion in small groups, which is especially most considered in Australian medical colleges (22). As indicated by the results of some studies carried in Canada and Australia, social accountability seems to be the most initiative strategy in developing curriculum and running admission process satisfying regional needs (1). This can successfully manage the existing unevenness and improve the positive and economic impacts demanded by the regions from medical schools. In total, for developing the culture of social accountability in medical schools, there is a necessity to recognize the existing needs and trends in order to design an appropriate program. As presented in the 10 solutions by the global consensus of social accountability of medical training, there is an emphasis on the development of outcomes-driven the curriculum, but it should be noted that changing and reforming the curriculum is a complex and time-consuming process. Furthermore, reforming the curriculum requires funding, facilities, 
curriculum specialists' presence, a new process for accepting students and community-based educational program $(6,23,24)$. However, various strategies are suggested to promote social accountability in the educational program, including the development of models and theoretical frameworks for curriculum accountability. Omid et al., in two studies on the use of general practitioners and family physicians, emphasized experience in determining the educational content required by doctors $(25,26)$. Lindgren stated in his article that, in medical education, there should be consideration of a curriculum for the training of general practitioners. Medical education at all three levels, such as general education, professional, and continuing education, should consider social accountability. Standards of the World Federation for Medical Education (WFME) have examined these three areas separately and have emphasized the importance of all three levels (27).

\section{Conclusions}

The findings of this study showed that training program needs for social accountability include four areas, i.e., 12 items for clinical area in which items such as " familiarizing students with common diseases, epidemiologic transition of disease, change of the disease burden in society" had the highest percentage of agreement (84.3\%), advocacy area included 10 item in which "community oriented medical education" had the highest percentage of agreement $(42.11 \%)$, within the scope of research there are 8 items such as " Conducting key researches regarding societies health-related issues" with the highest percentage of agreement (47.37\%), and in educational area 8 items "Using community-based, outpatient medical education, problem-oriented and holistic models" had highest percentage of agreement $(52.63 \%)$. The findings of this study were significant, and training managers and planners can apply these findings toward developing standards for general medical curriculum guaranteeing accountability at the School of Medicine. Supplementary research on the health needs of the population with a needs assessment methodology can be the appropriate path for future research on this topic.

\section{Acknowledgments:}

The researchers express their gratitude for the cooperation of the authorities at Mashhad University of Medical Sciences and the professors of medicine and the doctors who work in health centers that helped us during this study.

\section{Conflict of Interest:}

There is no conflict of interest to be declared.

\section{Authors' contributions:}

All authors contributed to this project and article equally. All authors read and approved the final manuscript.

\section{References:}

1) X C. N, I. R. Social accountability in medical education. Medical Education Scholarship Forum Proceedings. 2014.

2) A. J. Social Accountability: What Does the Evidence Really Say? Elsevier. 2015; 72: 346-61.

3) Ritz SA, Beatty K, Ellaway RH. Accounting for Social Accountability: Developing Critiques of Social Accountability within Medical Education. Educ Health (Abingdon). 2014; 27(2): 152-7. doi: 10.4103/13576283.143747, PMID: 25420977.

4) Yazdani S, Hoseini F, Homauni zand R. Reform in general medical degree curriculum 2008.

5) Awases M, Bailey R, C. B. Global Consensus for Social Accountability of Medical Schools. 2010.

6) Woollard B, Boelen C. Seeking impact of medical schools on health: meeting the challenges of social accountability. Med Educ. 2012; 46(1): 21-7. doi: 10.1111/j.1365-2923.2011.04081.x, PMID: 22150193.

7) Heck J. Defining and measuring the social accountability of medical schools. 1995.

8) Yamani N, Fakhari M. Social accountability in medical education curriculum: barriers and strategies. Iranian Journal of Medical Education. 2014; 13(12): 1082-98.

9) Emadzadeh A, Gholami H, Musavi Bazzaz M, Alamdaran A, Ebrahimi F. A study on the status of social accountability of Mashhad Medical School in domain of education of General Practice (2012). 2014.

10) Asghari F, Samadi A, Rashidian A. Medical ethics course for undergraduate medical students: a needs assessment study. J Med Ethics Hist Med. 2013;6. PMID: 24427484, PMCID: PMC3885212.

11) Broomfield D, Humphris GM. Using the Delphi technique to identify the cancer education requirements of general practitioners. Med edu. 2001; 35(10): 928-37. PMID: 11564196.

12) Yousefi-Nooraie R, Rashidian A, Keating JL, Schonstein E. Teaching evidence-based practice: the teachers consider the content. J Eval Clin Pract. 2007; 13(4): 569-75. doi: 10.1111/j.1365-2753.2007.00885.x, PMID: 17683298. 
13) Entezari A, Momtazmanesh N, Khojasteh A, Einollahi B. Toward social accountability of medical education in Iran. Iranian Journal of Public Health. 2009; 38(Suppl. 1): 27-8.

14) Strasser RP, Lanphear JH, McCready WG, Topps MH, Hunt DD, Matte MC. Canada's new medical school: The Northern Ontario School of Medicine: social accountability through distributed community engaged learning. Academic medicine. Acad Med. 2009; 84(10): 1459-64. doi: 10.1097/ACM.0b013e3181b6c5d7, PMID: 19881443.

15) Holmqvist M, Courtney C, Meili R, Dick A. Student-run clinics: Opportunities for interprofessional education and increasing social accountability. J Res Interprof Pract Educ. 2012; 2(3).

16) Murray E, Gruppen L, Catton P, Hays R, Woolliscroft JO. The accountability of clinical education: its definition and assessment. Med Education. 2000; 34(10): 871-9. doi: 10.1046/j.1365-2923.2000.00757.x

17) Wear D, Castellani B. The development of professionalism: curriculum matters. Acad Med. 2000; 75(6): 602-11. doi: 10.1097/00001888-200006000-00009, PMID: 10875504.

18) Dharamsi S, Ho A, Spadafora SM, Woollard R. The physician as health advocate: translating the quest for social responsibility into medical education and practice. Acad Med. 2011; 86(9): 1108-13. doi: 10.1097/ACM.0b013e318226b43b, PMID: 21785306.

19) Rezaeean M. A review of various aspects of socially accountable medical school. Rafsanjan University of Medical Sciences. 2013; 11(2).

20) Boelen C, Woollard B. Social accountability and accreditation: a new frontier for educational institutions. Medical education. 2009; 43(9): 887-94. doi: 10.1111/j.1365-2923.2009.03413.x, PMID: 19709014.

21) Collier R. Medical education needs overhaul to train more user-friendly physicians, AFMC says. CMAJ. 2010; 182(4): E201-3. doi: 10.1503/cmaj.109-3174, PMID: 20123806 , PMCID: PMC2831687.

22) ghafari R, Amini A, yazdani S, Alizadeh M, Salek Ranjbarzadeh F. Comparison of general physicion education plan in Iran medical school with some number of selected countries accredited in world. Iranian Journal of Medical Education. 2011; 11(7).

23) Ali SK, Baig LA. Problems and issues in implementing innovative curriculum in the developing countries: the Pakistani experience. BMC Med Educ. 2012; 12(1): 31. doi: 10.1186/1472-6920-12-31, PMID: 22591729, PMCID: PMC3395573.

24) Gibbs T, McLean M. Creating equal opportunities: the social accountability of medical education. Med teach. 2011; 33(8): 620-5. doi: 10.3109/0142159X.2011.558537, PMID: 21774647.

25) Omid A, Yamani N, heidari K, Mousavi A, mousavi T. Educatioal Needs of General Practitioners Who Enrolled as Family Physicion in National Family Medicine Program and Referral System. Iranian Journal of Medical Education. 2013; 13(6): 470-9.

26) Omid A, Haghjoy S, Eghbali B, Hosseini M. general practitioners and pationts disease in Isfahan: one step toward social accuntability. Iranian Journal of Medical Education. 2012; 11(9).

27) Lindgren S, Karle H. Social accountability of medical education: aspects on global accreditation. Med teach. 2011; 33(8): 667-72. doi: 10.3109/0142159X.2011.590246, PMID: 21774655. 